Prepared in cooperation with:

Florida Fish and Wildlife Conservation Commission

Northwest Florida Water Management District

Florida Department of Environmental Protection

U.S. Fish and Wildlife Service

\title{
Water-Level Decline in the Apalachicola River, Florida, from 1954 to 2004, and Effects on Floodplain Habitats
}

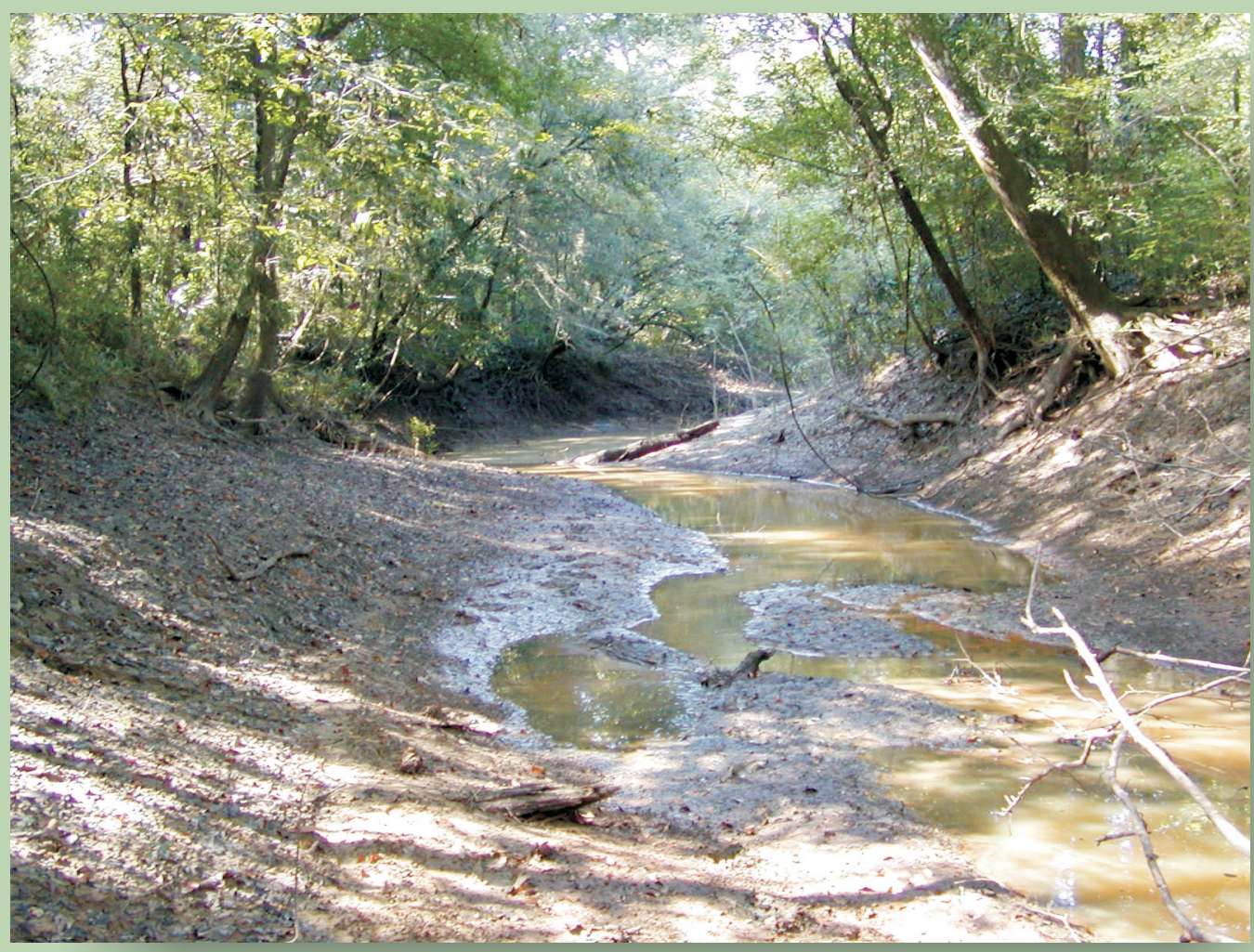

Scientific Investigations Report 2006-5173

U.S. Department of the Interior U.S. Geological Survey 